\title{
A Cross-sectional Survey of Urban and Rural Residents' Perceptions About the Medical System Services in a Middle Province of China
}

\section{Ying Pan}

Hebei Medical University

\section{Shaowen Li}

Hebei Medical University

Lina Yan

Hebei Medical University

\section{Sihua Chen}

Hebei Medical University

\section{Kejiang Pi}

Hebei Medical University

Biao Xi ( $\sim$ xb840927@163.com)

Hebei Medical University

\section{Research Article}

Keywords: The medical and health care system reform, difficult and expensive medical services, urban and rural residents, perception and satisfaction

Posted Date: November 10th, 2021

DOl: https://doi.org/10.21203/rs.3.rs-998685/v1

License: (c) (i) This work is licensed under a Creative Commons Attribution 4.0 International License. Read Full License 


\title{
A cross-sectional survey of urban and rural residents' perceptions about the medical system services in a middle province of China
}

\author{
Ying Pan ${ }^{1}$, Shaowen $\mathrm{Li}^{1,2}$, Lina Yan ${ }^{3}$, Sihua Chen ${ }^{1}$, Kejiang $\mathrm{Pi}^{1}$ and Biao $\mathrm{Xi}^{1,4, *}$ \\ 1 Medicine-education Coordination and Medical Education Center, Hebei Medical \\ University; Pan_ying123@163.com \\ 2 Foreign Language Teaching Department, Hebei Medical University; \\ Li15233622628@163.com \\ 3 School of Public Health, Hebei Medical University; naliyan@126.com \\ 4 Research Center for Health Development of Hebei Province; xb840927@163.com \\ * Correspondence: xb840927@163.com; Tel.: 0311-86266473
}

Author Contributions: Conceptualization, Ying Pan and Biao Xi; methodology, Lina Yan.; software, Lina Yan; formal analysis, Sihua Chen; investigation, Ying Pan and Sihua Chen; resources, Kejiang Pi; data curation, Lina Yan; writing-original draft preparation, Ying Pan and Shaowen Li; writing - review and editing, Ying Pan, Shaowen Li and Biao $\mathrm{Xi}$; project administration, Biao $\mathrm{Xi}$ and Kejiang Pi. All authors have read and agreed to the published version of the manuscript. 


\begin{abstract}
:
Background: To investigate urban and rural residents' perceptions on the issue of "difficult access to quality medical services and expensive medical bills" (difficult and expensive medical services) 10 years after the implementation of medical and health care system reform in China.
\end{abstract}

Methods: we conducted a cross-sectional questionnaire survey of residents in a middle province of China. Multi-stage stratified random sampling was utilized to sample a total of 1968 residents of three cities in the middle province in July 2019.

Results: Residents in the province were highly satisfied with the solution of "difficult and expensive medical services", with the satisfaction rate reaching $70 \%$. However, satisfaction differed among the surveyed cities. $83.4 \%$ of the residents reported "difficult and expensive medical services"as their current major concern. Complex medical procedures (31.25\%) and high inspection costs (51.68\%) were the main reasons for "difficult and expensive medical services". Other reasons include the provision of medical and health resources, the service awareness of medical and health care personnel, people's health needs, and the perceptions of health, etc.

Conclusions: The issue of "difficult and expensive medical services" is a social issue requiring constant attention.

Keywords: The medical and health care system reform; difficult and expensive medical services; urban and rural residents; perception and satisfaction

\title{
1. Background
}

Since the first implementation in 2009, the new medical and health care system reform in China has been constantly implemented to protect and promote the health of urban and rural residents. In a single middle province in China, the government has invested a total of 360 billion RMB in medical reform funds, with an average annual increase of $17.96 \%$, which is $2.9 \%$ higher than the average annual increase of the general public budget. Through a series of actions and measures, the new medical and health care system reform in the middle province of China has witnessed fruitful results and the issue of "difficult access to quality medical services and expensive medical bills" (difficult and expensive medical services) has been alleviated to a certain extent. The steps taken include comprehensive reform of hospitals, the universal medical insurance system, the three-level diagnosis and treatment system, and most importantly, the assessment of the proportion of drugs and the prepayment system for medical insurance funds. However, with the increasing health needs of the public, the total amount of medical and health resources in the province is still insufficient and the allocation is uneven. The issue of difficult and expensive medical services still exist as a sustainability problem, which has yet been fundamentally solved from the system and mechanism. The study aims to investigate the perceptions of urban and rural residents in a middle province in China on the level of medical security, medical burden, per capita medical expenses, etc., to make a descriptive analysis of urban and rural residents' perceptions and satisfaction about the medical system services, providing insights for optimizing the new medical and health care reform in China.

\section{Materials and Methods}

\subsection{Materials}


A total of 1968 urban and rural residents of three cities in the middle province of China were randomly surveyed, according to the sample content calculation formula of the estimated overall rate of stratified sampling (shown below). All questionnaires were administered and collected on the spot. A total of 1968 questionnaires were distributed, and 1968 questionnaires were collected, of which 1968 were valid questionnaires, with $100 \%$ recovery rate and $100 \%$ efficiency rate. Written informed consents were obtained from all the participants. The Cronbach's coefficient was utilized to evaluate the overall and internal consistency of the questionnaire. The Cronbach's coefficient was 0.814 and the questionnaire had a decent confidence.

Sample content calculation formula: total number of respondents

$$
n=\frac{\left(\sum W_{i} \sqrt{p_{i} q_{i}}\right)^{2}}{V+\sum \frac{W_{i} p_{i} q_{i}}{N}}
$$

Number of participants in three municipalities

$$
n_{i}=\frac{n N_{i} \sqrt{p_{i} q_{i}}}{\sum\left(N_{i} \sqrt{p_{i} q_{i}}\right)}
$$

In the formula, $W_{i}=\frac{N_{i}}{N} . N_{i}, p_{i}, q_{i}$ refers to the number of cases of layer i, positive rate and negative rate, respectively. In this study, ${ }^{N_{i}}$ refers to the population of the three cities

studied. $p_{i}$ is estimated by the pilot survey of the three cities' residents and $q_{i}$ means 1- ${ }^{{ }_{i}}$.N is the total number of cases (i.e. the total population of the three cities studied). $V$ is the variance of

the estimated population rate and $V=\left(\delta / u_{\alpha / 2}\right)^{2} . \quad \delta_{\text {stands for the allowable error }(5 \% \text { for }}$ this study). ${ }^{\alpha}$ stands for type I error (generally 0.05) and $u_{\alpha / 2}$ was 1.96 .

The major dimensions of the questionnaire were shown in Table 1.

Table 1. Questionnaire dimensions

\begin{tabular}{ll}
$\begin{array}{l}\text { Demographic } \\
\text { information }\end{array}$ & Your age \\
& Your gender \\
& Your level of education \\
& Your household registry \\
& Your monthly income \\
\hline
\end{tabular}

Level of concern Are you concerned with "difficult and expensive medical services"? 
Do you think you've experienced "difficult and expensive medical services"?

Difficult quality What in your opinion are the reasons for access to quality medical medical services services?

The main factors you consider when choosing a healthcare provider

Which level of hospital do you and your family often choose to seek medical attention at?

Which level of hospital do you think is the most difficult to have access to?

Expensive Possible reasons for expensive medical bills

medical bills

The average annual medical bills for you or your family

Satisfaction Are you satisfied with the government's solution to the problem of "difficult and expensive medical services"?

What measures do you think will help alleviate "difficult and expensive medical services"?

\subsection{Methods}

Using multi-stage stratified random sampling method, we conducted a cross-sectional questionnaire survey of urban and rural residents in three cities of a middle province in China. A self-devised questionnaire was administered as a survey tool to investigate residents' utilization of medical and health care services, their health status, their medical burden, and their perceptions on "difficult and expensive medical services". In order to control the quality of the survey, unified training of investigators, unified standards on the filling of questionnaires were employed during the random sampling process. At the end of the survey, the heads of the investigation teams reviewed $2 \%$ of the collected questionnaires and the project leader reviewed $1 \%$ of them.

After data collection, the database was established using EpiData 3.1 and all the data were double-entered. The SPSS 20.0 statistical analysis software was used for data analysis. A descriptive analysis of the data was conducted by frequency (composition ratio), the comparison between counting data groups was based on the test or Fisher's exact probability method, and the test level of $p<0.05$ was considered statistically significant.

\section{Results}

This section may be divided by subheadings. It should provide a concise and precise description of the experimental results, their interpretation, as well as the experimental conclusions that can be drawn.

\subsection{Demographic information of the residents in the middle province of China}


A total of 1968 respondents in a middle province of China were surveyed in this study. Among them, 699 residents were from Tangshan(35.52\%), 578 from Zhangjiakou (29.37\%) and 691 from Xingtai (35.11\%), and the specific sample distribution was shown in Table 2.

Table 2. Distribution of subjects

\begin{tabular}{|c|c|c|}
\hline City & County & No. of residents (\%) \\
\hline \multirow[t]{5}{*}{ Tangshan } & Fengnan & 208 (10.57\%) \\
\hline & Luannan & $204(10.37 \%)$ \\
\hline & Qian'an & $216(10.98 \%)$ \\
\hline & Tangshan & $71(3.61 \%)$ \\
\hline & Total & $699(35.52 \%)$ \\
\hline \multirow[t]{5}{*}{ Xingtai } & Lincheng & $22(11.18 \%)$ \\
\hline & Qinghe & $21(10.72 \%)$ \\
\hline & Weixian & $193(9.81 \%)$ \\
\hline & Xingtai & $67(3.40 \%)$ \\
\hline & Total & $691(35.11 \%)$ \\
\hline \multirow[t]{5}{*}{ Zhangiiakou } & Huailai & $206(10.47 \%)$ \\
\hline & Kangbao & $78(3.96 \%)$ \\
\hline & Weixian & $22(11.23 \%)$ \\
\hline & Zhangjiakou & $73(3.71 \%)$ \\
\hline & Total & $578(29.37 \%)$ \\
\hline
\end{tabular}

Of all the respondents, 1,147 (58.28\%) were male and 821 (41.72\%) were female. 1208 urban and rural residents $(61.38 \%$ ) had a monthly income of less than 1,000 RMB, 617 residents $(31.35 \%)$ earned a monthly income of $1000-3000 \mathrm{RMB}$, whereas $143(7.26 \%)$ of the residents had a monthly income of above 3000 RMB. There were 1010 participants aged 60 and over (51.32\%), 602 (30.59) of residents aged 40-60 years and 356 (18.09\%) of residents aged 40 and under. The residents' level of education was mainly junior high schools and below, accounting for $79.12 \%$ of the total survey population. $83.23 \%$ of the surveyed residents were rural residents. The demographic characteristics of the respondents was shown in Table 3. 
Table 3. Demographic characteristics of the surveyed residents

\begin{tabular}{|c|c|c|}
\hline Variable & Category & Total $(\%)$ \\
\hline \multirow{4}{*}{ Age } & Below 20 & $35(1.78 \%)$ \\
\hline & $20-40$ & $321(16.31 \%)$ \\
\hline & $40-60$ & $602(30.59 \%)$ \\
\hline & Above 60 & $1010(51.32 \%)$ \\
\hline \multirow{2}{*}{ Gender } & Male & $1147(58.28 \%)$ \\
\hline & Female & $821(41.72 \%)$ \\
\hline \multirow{4}{*}{$\begin{array}{l}\text { Level of } \\
\text { education }\end{array}$} & Primary school and below & $908(46.14 \%)$ \\
\hline & Junior high school & $649(32.98 \%)$ \\
\hline & High school & $275(13.97 \%)$ \\
\hline & College and above & $136(6.91 \%)$ \\
\hline \multirow{2}{*}{$\begin{array}{l}\text { Household } \\
\text { registry }\end{array}$} & Rural residents & $1638(83.23 \%)$ \\
\hline & Urban residents & $330(16.77 \%)$ \\
\hline \multirow{4}{*}{$\begin{array}{l}\text { Monthly } \\
\text { income }\end{array}$} & Below 1000 & $1208(61.38 \%)$ \\
\hline & $1000-3000$ & $617(31.35 \%)$ \\
\hline & $3000-5000$ & $125(6.35 \%)$ \\
\hline & 5000 and above & $18(0.91 \%)$ \\
\hline
\end{tabular}

\subsection{Level of concern with "difficult and expensive medical services"}

The survey found that the 1968 rural and urban residents had an overall concern rate of the issue "difficult and expensive medical services" as high as $83.4 \%$. The proportion of the surveyed residents who "never paid attention to the problem", "general concern"or "much concern"with the issue was 16.67 percent, 32.67 percent and 50.66 percent, respectively. Residents' level of concern with "difficult and expensive medical services" was stratified and analyzed according to age, sex, education, household registry and monthly income. Results showed statistically significant differences on people with different ages, level of education and household registry on their level of concern with "difficult and expensive medical services" $(p<0.05)$. In terms of different level of education, residents with lower than primary school degree showed little difference on "general concern" and "eager concern", whereas residents with higher than junior high school degree mainly showed "eager concern" to the issue of "difficult and expensive medical services". Though there was significant difference on residents living in different cities and counties on their level of concern $(p<0.05)$, rural and 
urban residents living in different cities mainly showed "eager concern" with the issue of "difficult and expensive medical services" (as shown in Table 4).

Table 4. Residents' level of concern with "difficult and expensive medical services".

\begin{tabular}{|c|c|c|c|c|c|c|c|}
\hline & & $\begin{array}{l}\text { Little } \\
\text { concern } \\
\end{array}$ & $\begin{array}{l}\text { Major } \\
\text { concern }\end{array}$ & $\begin{array}{l}\text { General } \\
\text { concern }\end{array}$ & Total & $\chi^{2}$ & $\mathrm{p}$ \\
\hline & Below 20 & $3(8.6 \%)$ & $12(34.3 \%)$ & $20(57.1 \%)$ & $35(1.78 \%)$ & 69.808 & $<0.0001$ \\
\hline \multirow[t]{3}{*}{ Age } & $20-40$ & $22(6.9 \%)$ & $210(65.4 \%)$ & $89(27.7 \%)$ & $321(16.31 \%)$ & & \\
\hline & $40-60$ & $92(15.3 \%)$ & $330(54.8 \%)$ & $180(29.9 \%)$ & $602(30.59 \%)$ & & \\
\hline & Above 60 & $211(20.9 \%)$ & $445(44.1 \%)$ & $354(35.0 \%)$ & $1010(51.32 \%)$ & & \\
\hline \multirow[t]{2}{*}{ Gender } & Male & $186(16.2 \%)$ & $584(50.9 \%)$ & $377(32.9 \%)$ & $1147(58.28 \%)$ & 0.402 & 0.818 \\
\hline & Female & $142(17.3 \%)$ & $413(50.3 \%)$ & $266(32.4 \%)$ & $821(41.72 \%)$ & & \\
\hline \multirow{4}{*}{$\begin{array}{l}\text { Level of } \\
\text { education }\end{array}$} & $\begin{array}{l}\text { Primary } \\
\text { school and } \\
\text { below }\end{array}$ & $246(27.1 \%)$ & $332(36.6 \%)$ & $330(36.3 \%)$ & $908(46.14 \%)$ & 193.602 & $<0.0001$ \\
\hline & $\begin{array}{l}\text { Junior high } \\
\text { school }\end{array}$ & $60(9.2 \%)$ & $385(59.3 \%)$ & $204(31.4 \%)$ & $649(32.98 \%)$ & & \\
\hline & High school & $15(5.5 \%)$ & $194(70.5 \%)$ & $66(24.0 \%)$ & $275(13.97 \%)$ & & \\
\hline & $\begin{array}{l}\text { College } \\
\text { education } \\
\text { and above }\end{array}$ & $7(5.1 \%)$ & $86(63.2 \%)$ & $43(31.6 \%)$ & $136(6.91 \%)$ & & \\
\hline \multirow{2}{*}{$\begin{array}{l}\text { Household } \\
\text { registry }\end{array}$} & Rural & $306(18.7 \%)$ & $786(48.0 \%)$ & $546(33.3 \%)$ & $1638(83.23 \%)$ & 38.893 & $<0.0001$ \\
\hline & Urban & $22(6.7 \%)$ & $211(63.9 \%)$ & $97(29.4 \%)$ & $330(16.77 \%)$ & & \\
\hline \multirow{4}{*}{$\begin{array}{l}\text { Monthly } \\
\text { income }\end{array}$} & Below 1000 & $226(18.7 \%)$ & $596(49.3 \%)$ & $386(32.0 \%)$ & $1208(61.38 \%)$ & 11.979 & 0.062 \\
\hline & $1000-3000$ & $88(14.3 \%)$ & $322(52.2 \%)$ & $207(33.5 \%)$ & $617(31.35 \%)$ & & \\
\hline & $3000-5000$ & $13(10.4 \%)$ & $70(56.0 \%)$ & $42(33.6 \%)$ & $125(6.35 \%)$ & & \\
\hline & $\begin{array}{l}5000 \quad \text { and } \\
\text { above }\end{array}$ & $1(5.6 \%)$ & $9(50.0 \%)$ & $8(44.4 \%)$ & $18(0.91 \%)$ & & \\
\hline \multirow[t]{2}{*}{ Cities } & Tangshan & $89(12.7 \%)$ & $408(58.4 \%)$ & $202(28.9 \%)$ & $699(35.52 \%)$ & 28.689 & $<0.0001$ \\
\hline & Xingtai & $124(17.9 \%)$ & $320(46.3 \%)$ & $247(35.7 \%)$ & $691(35.11 \%)$ & & \\
\hline
\end{tabular}


$\mathrm{p}<0.05$ indicated statistically significant differences.

3.3. The surveyed residents' satisfaction with government's solution of "difficult and expensive medical services"

$70.44 \%$ of the respondents were generally satisfied or satisfied with the government's solution of "difficult and expensive medical services", while 20.68 percent of the residents were dissatisfied (Figure 1).

Figure 1. Residents' proportion of satisfaction with government's solution of the issue.

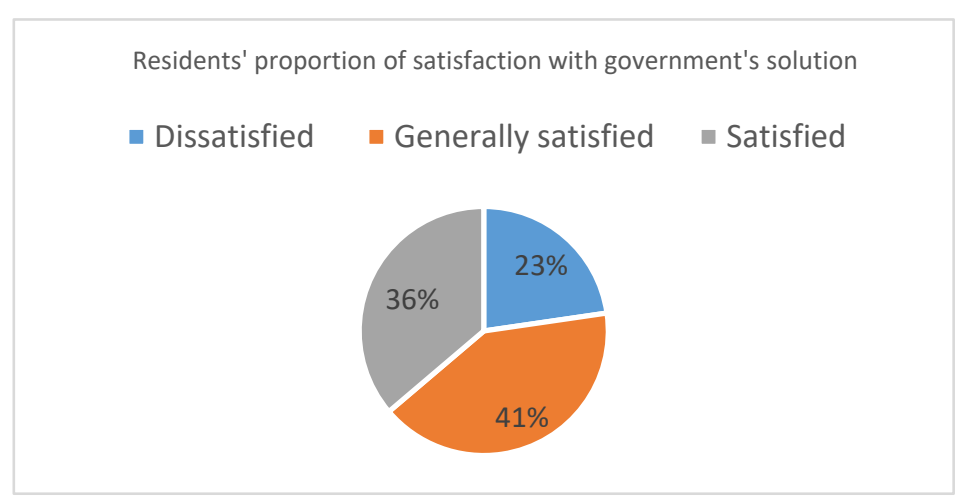

According to the urban cluster statistics, residents in Tangshan were less satisfied with the government's solution to the problem of "difficult and expensive medical care", with 36.96 percent of residents saying they were not satisfied and only 19.05 percent of the residents were satisfied. Residents of Zhangiiakou were more satisfied with the government's solution to "difficult and expensive medical services", with $71.43 \%$ of residents reporting almost satisfied or satisfied and only $18.99 \%$ of the residents not being satisfied. Residents of Xingtai showed the highest satisfaction to the government's solution of "difficult and expensive medical services", with 85.67 percent of residents satisfied or generally satisfied, and only 5.64 percent dissatisfied (see Table 5).

Table 5. Residents' satisfaction with the government's solution of the issue

\begin{tabular}{lcllll} 
& Satisfied & $\begin{array}{l}\text { Generally } \\
\text { satisfied }\end{array}$ & Dissatisfied & $\chi^{2}$ & $\mathrm{p}$ \\
\hline Tangshan & $\begin{array}{c}133 \\
(19.05 \%)\end{array}$ & $238(34.10 \%)$ & $258(36.96 \%)$ & 239.969 & $<0.0001$ \\
Xingtai & $\begin{array}{c}304 \\
(43.99 \%)\end{array}$ & $288(41.68 \%)$ & $39(5.64 \%)$ & \\
Zhangjiakou & $\begin{array}{c}201 \\
(35.02 \%)\end{array}$ & $209(36.41 \%)$ & $109(18.99 \%)$ & \\
& & & & \\
& & & & \\
\end{tabular}


$\mathrm{p}<0.05$ indicated statistically significant differences.

\subsection{Residents' perceived reasons of "difficult and expensive medical services"}

\subsubsection{Resident's perceived reasons of "difficult access to quality medical services"}

Of the 1968 inhabitants of the three cities surveyed, 1,064 (54.06\%) considered it difficult to see a doctor, whereas 904 (45.94\%) considered it not difficult. Further stratification analysis showed that, except those with lower than high school degree, the rest of the surveyed residents with different ages, educational backgrounds, household registry, and monthly income all believed that the problem of "difficult access to quality medical services" still existed in the middle province in China (shown in Table 6).

Table 6. Residents' perceptions of "difficult access to quality medical services".

\begin{tabular}{|c|c|c|c|c|c|}
\hline & & Difficult & Not difficult & $\chi^{2}$ & $p$ \\
\hline \multirow[t]{3}{*}{ Age } & Below 40 & $231(65.6 \%)$ & $121(34.4 \%)$ & & \\
\hline & $40-60$ & $323(54.7 \%)$ & $267(45.3 \%)$ & 22.323 & $<0.0001$ \\
\hline & Above 60 & $510(51.1 \%)$ & $489(48.9 \%)$ & & \\
\hline \multirow[t]{2}{*}{ Gender } & Male & $628(55.7 \%)$ & $499(44.3 \%)$ & \multirow[b]{2}{*}{0.891} & \multirow[b]{2}{*}{0.345} \\
\hline & Female & $436(53.6 \%)$ & $378(46.4 \%)$ & & \\
\hline \multirow{4}{*}{$\begin{array}{l}\text { Level of } \\
\text { education }\end{array}$} & $\begin{array}{l}\text { Primary } \\
\text { school and } \\
\text { below }\end{array}$ & $406(45.4 \%)$ & $488(54.6 \%)$ & \multirow{4}{*}{62.346} & \multirow{4}{*}{$<0.0001$} \\
\hline & $\begin{array}{l}\text { Junior high } \\
\text { school }\end{array}$ & $389(60.8 \%)$ & $251(39.2 \%)$ & & \\
\hline & High school & $177(65.1 \%)$ & $95(34.9 \%)$ & & \\
\hline & $\begin{array}{l}\text { College } \\
\text { education } \\
\text { and above }\end{array}$ & $92(68.1 \%)$ & $43(31.9 \%)$ & & \\
\hline \multirow{2}{*}{$\begin{array}{l}\text { Household } \\
\text { registry }\end{array}$} & Rural & $835(51.7 \%)$ & $780(48.3 \%)$ & \multirow{2}{*}{37.654} & \multirow{2}{*}{$<0.0001$} \\
\hline & Urban & $229(70.2 \%)$ & $97(29.8 \%)$ & & \\
\hline \multirow{3}{*}{$\begin{array}{l}\text { Monthly } \\
\text { income }\end{array}$} & Below 1000 & $612(51.5 \%)$ & $576(48.5 \%)$ & \multirow{3}{*}{14.151} & \multirow{3}{*}{$<0.0001$} \\
\hline & $1000-3000$ & $363(59.3 \%)$ & $249(40.7 \%)$ & & \\
\hline & $3000-5000$ & $89(63.1 \%)$ & $52(36.9 \%)$ & & \\
\hline
\end{tabular}




\begin{tabular}{lllll} 
City & Tangshan & $510(73.8 \%)$ & $181(26.2 \%)$ & \\
Xingtai & $247(36.5 \%)$ & $429(63.5 \%)$ & 192.199 & $<0.0001$ \\
& Zhangjiakou & $307(53.5 \%)$ & $267(46.5 \%)$ & \\
\hline
\end{tabular}

To further understand the reasons why the 1064 residents surveyed considered it "difficult to see a doctor", the reasons were listed in Table 7. Specifically, 31.3\% of the surveyed residents thought the consultation procedure was cumbersome, $27.4 \%$ of them thought the cost was too high, $27.1 \%$ of the residents reported it was difficult to register for a doctor due to the large number of patients, $23.2 \%$ of them reported difficult to see an expert, $22.3 \%$ reported long waiting time, $9.9 \%$ reported difficult hospitalization, $6.3 \%$ of the surveyed residents complained about health care workers' bad manners and poor attitudes, $6.0 \%$ of them reported long distance of medical facilities, $4.2 \%$ thought medical staff lack professional competency, and $3.8 \%$ of participants reported lack of guidance and information on medical services ( shown in Table 7).

Table 7. Residents' perceived reasons for "difficult access to quality medical services".

\begin{tabular}{ll}
\hline Reasons & Proportions \\
\hline Cumbersome consultation procedure & $31.25 \%$ \\
High cost & $27.44 \%$ \\
Large number of patients, difficult for registry & $27.08 \%$ \\
Difficult to see an expert & $23.17 \%$ \\
Long waiting time & $22.31 \%$ \\
Difficult for hospitalization & $9.91 \%$ \\
Health care workers' poor attitudes & $6.30 \%$ \\
\hline Long distance to medical facilities & $6.00 \%$ \\
\hline
\end{tabular}

\subsubsection{Residents' perceived reasons of "expensive medical services"}

Of the 1968 inhabitants of the three cities surveyed, 1,409 (71.60\%) considered they experienced "expensive medical services", whereas 559 (28.40\%) considered it not expensive. Further stratification analysis showed residents with different ages, educational background, household registry, and monthly income all believe that the problem of "expensive medical services" still existed in the middle province in China (shown in Table 8). 
Table 8. Residents' perceptions of "expensive medical services".

\begin{tabular}{|c|c|c|c|c|c|}
\hline & & Expensive & Not expensive & $\chi^{2}$ & $\mathrm{p}$ \\
\hline \multirow[t]{3}{*}{ Age } & Below 40 & $289(82.10 \%)$ & $63(17.90 \%)$ & 26.804 & $<0.0001$ \\
\hline & $40-60$ & $439(74.41 \%)$ & $151(25.59 \%)$ & & \\
\hline & Above 60 & $681(68.17 \%)$ & $318(31.83 \%)$ & & \\
\hline \multirow[t]{2}{*}{ Gender } & Male & $825(73.20 \%)$ & $302(26.80 \%)$ & 0.505 & 0.477 \\
\hline & Female & $584(71.74 \%)$ & $230(28.26 \%)$ & & \\
\hline \multirow{4}{*}{$\begin{array}{l}\text { Level of } \\
\text { education }\end{array}$} & $\begin{array}{l}\text { Primary } \\
\text { school and } \\
\text { below }\end{array}$ & $566(63.31 \%)$ & $328(36.69 \%)$ & 73.838 & $<0.0001$ \\
\hline & $\begin{array}{l}\text { Junior high } \\
\text { school }\end{array}$ & $507(79.22 \%)$ & $133(20.78 \%)$ & & \\
\hline & High school & $221(81.25 \%)$ & $51(18.75 \%)$ & & \\
\hline & $\begin{array}{l}\text { College } \\
\text { education } \\
\text { and above }\end{array}$ & $115(85.19 \%)$ & $20(14.81 \%)$ & & \\
\hline \multirow{2}{*}{$\begin{array}{l}\text { Household } \\
\text { registry }\end{array}$} & Rural & $1132(70.09 \%)$ & $483(29.91 \%)$ & 30.171 & $<0.0001$ \\
\hline & Urban & $277(84.97 \%)$ & $49(15.03 \%)$ & & \\
\hline \multirow{3}{*}{$\begin{array}{l}\text { Monthly } \\
\text { income }\end{array}$} & Below 1000 & $824(69.36 \%)$ & $364(30.64 \%)$ & 16.079 & $<0.0001$ \\
\hline & $1000-3000$ & $475(77.61 \%)$ & $137(22.39 \%)$ & & \\
\hline & $3000-5000$ & $110(78.01 \%)$ & $31(21.99 \%)$ & & \\
\hline \multirow[t]{3}{*}{ City } & Tangshan & $603(87.26 \%)$ & $88(12.74 \%)$ & 133.623 & $<0.0001$ \\
\hline & Xingtai & $403(59.62 \%)$ & $273(40.38 \%)$ & & \\
\hline & Zhangjiakou & $403(70.21 \%)$ & $171(29.79 \%)$ & & \\
\hline
\end{tabular}

To further investigate 1409 residents reporting "expensive medical services", we found 51.68\% of them thought the examination fees were high, $48.22 \%$ of them thought the drugs were expensive, 32.52 percent of residents complained personal out-of-pocket rates were high, 16.46 per cent of them had high standards for medical services, $15.35 \%$ of them thought over-medical care led to the high medical costs, $10.06 \%$ of the residents thought the health 
insurance coverage was low, $10.06 \%$ thought the medical cost did not match personal income, and $0.46 \%$ thought hospitalization fees were expensive (as shown in Table 9).

Table 9. Residents' perceived reasons for "expensive medical services".

\begin{tabular}{lc}
\hline Reasons & Proportions \\
\hline High examination fees & $51.68 \%$ \\
Expensive drugs & $48.22 \%$ \\
High personal out-of-pocket rates & $32.52 \%$ \\
High standards for medical services & $16.46 \%$ \\
Over-medical care & $15.35 \%$ \\
Low health insurance coverage & $10.06 \%$ \\
Personal income & $10.06 \%$ \\
High hospitalization fees & $0.46 \%$ \\
\hline
\end{tabular}

\section{Discussion}

\subsection{Residents' general perceptions of "difficult and expensive medical services"}

"Difficult medical service" refers to the dissatisfied situation of urban and rural residents' various medical service needs[1], which can be divided into two situations. On one hand, the difficulty for seeking medical service was due to lack of different levels of medical services provided or inadequate medical service. On the other hand, patients in need of health care service lack access to quality medical service though different level of medical services are provided.

"Expensive medical services" refers to the situation where medical expenses exceed patient's ability to pay, and therefore results in the perception of "expensive to see a doctor"[2]. The main reasons include insufficient payment ability of patients, and they find it hard to pay the high but reasonable medical expenses. Other reasons include the unreasonable medical expenses caused by the excessive medical treatment of medical institutions, which exceeded the patients' payment ability and their psychological expectations.

Through investigating rural and urban residents' perceptions about "difficult and expensive medical services" in a middle province in China, we found various subjective and objective reasons, including the provision of medical and health care resources, medical staff's service awareness, people's health needs and perceptions of health. The findings also indicated differences between regions. In general, the issue of "difficult and expensive medical services" is perceived as a relative social problem which requires constant attention and gradual solution. 


\subsection{The status quo of "difficult and expensive medical services" in the middle province of China}

The issue of "expensive medical service" has been considerably alleviated but it still exists. Since the new medical and health system reform, the issue of "expensive medical service" has been considerably alleviated in the middle province of China, accompanied with the improvement of the medical and health care system, great efforts to alleviate poverty, and the increasing income. In terms of residents' satisfaction with government's efforts to address "difficult and expensive medical services", $70.44 \%$ of the surveyed residents reported they were satisfied. However, it is noteworthy that residents of different cities showed different levels of satisfaction, with only 19.05 percent of Tangshan residents reporting satisfied, 71.43 percent of residents in Zhangjiakou satisfied, and 85.67 percent of residents of Xingtai satisfied. Over the past decade, the public's recognition of primary health care and their sense of health fulfillment has been significantly improved. However, $71.6 \%$ of the surveyed residents of the middle province thought the issue of "expensive medical service" still exist, as the old problems leading to "expensive medical care" still exist.

The issue of "difficult medical service" is a local phenomenon. Findings from the study showed that the consultation and treatment procedure of general common diseases and multiple morbidity in the province is smooth with few difficult problems. However, the phenomenon of "difficult to see a doctor" is widely seen in the referral process at all levels of medical institutions. Data analysis of the survey indicated that generally, $54.06 \%$ of the residents found it difficult to see a doctor, of which 51.7 percent were rural residents. In China, the allocation of medical resources is uneven, with low-level medical institutions commonly seen in rural areas. In contrast, urban medical institutions are more diverse in layering, which involves more diversion and transfer of patients, medical choices and other issues. Large cities, in particular, are concentrated with high-quality medical resources and numerous medical options, are more exposed to over medical treatment and lack of proper hierarchical diagnosis and treatment system, as can be shown in the survey. Some of the subjective reasons include patients' irrational pursuit of ideal medical outcomes and non-objective judgment of medical quality of different medical institutions. Therefore, "small disease being largely treated" becomes a common phenomenon, which further leads to waste of medical and public health resources. From the objective aspect, in the comparison of population's perceptions about "difficult medical service", $63.1 \%$ of those with a monthly income of $3000 \mathrm{RMB}$ and above reported difficult to see a doctor, which was higher than those with a monthly income of lower than $1000 \mathrm{RMB}(51.5 \%)$.

In terms of income distribution, low-income people are mainly distributed in rural areas, and high-income people account for the majority of urban areas, which also reflects the more plight urban residents encountered when accessing medical services. Research also showed the issue of "difficult to see a doctor" is mainly reflected in the three-level A hospitals. When residents of the middle province go to large prestigious hospitals in large cities, such as Beijing or Tianjin, they are more likely to encounter "difficult medical service" because of the cumbersome medical consultation procedure, large number of patients, and registration difficulties, etc. For example, 73.8 percent of the respondents in Tangshan City (near Beijing-Tianjin area) found it difficult to see a doctor, and the proportion was much lower (36.5 percent) among respondents in Xingtai City (far Beijing-Tianjin area). This in some ways shows that among people/regions with high cross-regional demand for medical treatment, although it seems to have more choices, more choice and comparisons, more irrational pursuit may occur in their medical consultation and treatment process. Therefore, we come to realize that high-quality medical resources are relatively scarce in any parts of the country, and the blind pursuit of high-quality medical resources and the formation of local "difficult to see a doctor" phenomenon in a certain stage of development is inevitable.

\subsection{Reasons for "difficult and expensive medical services" in the surveyed province}




\subsubsection{The provision of medical services}

In this study, we investigated three cities in the middle province of China, and the results showed that the significant gap between urban and rural economy, the unbalanced urban and rural development, the uneven allocation of health care services and resources were among the direct reasons leading to "difficult medical services". In terms of the allocation of health resources, a remarkable gap between urban and rural economic development is widely acknowledged. High-quality medical and health care resources are mainly concentrated in large and medium-sized cities, while medical service institutions in county-level, township-level, and village-level are remarkably insufficient. The shortage not only lies in the insufficient investment of medical facilities, but also in the insufficiency of effective training and introducing medical professionals, which makes it harder to attract and retain medical professionals.

Meanwhile, as the new medical service and health system reform continues, the expenses of drugs, consumables, etc., has been controlled, but the phenomenon of inflated prices of certain drugs still exists. It is noteworthy that some special drugs for major diseases are often not listed in medical insurance coverage catalogue.[3] Certain drugs used for the treatment of malignant tumors, though very high in expense, are not covered by medical insurance. Thus the cost of those types of drugs not enlisted in medical insurance coverage should be entirely borne by the individuals. Besides, the prices of some commonly used drugs, monopoly drugs, and some less commonly used but essential first aid drugs, are inflated, which, to some extent, accelerate the rise of medical costs.

\subsubsection{The demand of medical services}

The unreasonable flow of patients brought about by the increasing demand for health has increased the cost of medical care. The issue of "difficult and expensive medical services" arises from the gap between the health demand of the demand side and the medical supply of the supply side. With the development of medical science and technology, new materials of high-tech, new equipment and facilities are constantly being applied to medical care practice, which provides greater and more effective protection for human health, and will inevitably bring about the significant rise of medical treatment.[4]

Findings in the study showed that $35 \%$ of patients with major diseases were referred to well-known provincial hospitals outside the county, among which, nearly $60 \%$ of those were referred to prestigious medical institutions in Beijing, Tianjin, Shanghai and prestigious medical institutions in other provinces. In the past three years, the surveyed middle province of China has a higher referral rate to hospitals in Beijing, Tianjin, etc., than the surrounding provinces of Shanxi and Shandong[5]. This has something to do with the location of the surveyed middle province. As the province is closely located to first-tier cities of Beijing and Tianjin, patients has more convenient referral choices. However, the referral process is often not that smooth and phenomenon like cross-level referral occur frequently.

Besides, in the survey province, the three-level diagnosis and treatment system has not yet formed, and there lack effective interaction between medical insurance and the three level diagnosis and treatment system. A large proportion of patients still haven't form a sense of three level medical service system, which further results in the the issue of "difficult and expensive medical services".

\subsubsection{Residents' payment ability}

Various reasons leads to patients' over attention and psychological imbalance towards the distribution of income. Specifically, the gap of the level of economic development between urban and rural areas, the employment problem of the labor force, the imperfect social 
security system, the contradiction and incongruity of economic development, ecological situation and the natural resources are intertwined. Data showed that in 2010, the per capita consumption expenditure of urban households in the middle province of China was 10,318.3 RMB, of which the expenditure on health care was $923.8 \mathrm{RMB}$, accounting for 0.09 percent of the whole expenditure. In 2019, however, the per capita consumption expenditure of urban households in the province was $23,483.1 \mathrm{RMB}$, of which the health care cost was 1,883.7 RMB, accounting for $0.08 \%$. It can be seen that in the past ten years, the proportion of medical expenditure has decreased, but a large number of patients are still extremely sensitive to medical costs, and even perceive health care bills as unnecessary household expenditure. A very remarkable complex exists that on one hand, health care professionals consider medical fees are relatively low, which is inconsistent with their intellectual efforts and professional inputs, whereas on the other hand, some patients in the blind pursuit of high-quality medical and health care resources tend to have the perception of "difficult and expensive to see a doctor".

\subsubsection{Residents' perceptions of health}

Some Chinese citizens' perceptions of health include indifferent health care awareness and lack of concept of prevention. And those diseases which were minor originally might become incurable major diseases. Though health is very important to everyone, people's degree of attention can be different. It is all a personal choice and determination whether to treat the diseases and when. Some residents do not recognize the harm of the disease and unwilling to receive immediate and proper treatment when the condition is still in the treatable phase may also be an important reason leading to the issue of "difficult and expensive medical services".

In the survey, there are medical staff saying hypertension is completely controllable as a pathological state, but some patients do not pay attention to the control of the condition, and they won't appeal to medical attention and treatment until the brain haemorrhage. This phenomenon would undoubtedly result in a huge increase in medical costs. Statistics also show that nearly 20 percent of residents in rural areas still pay little or no attention to health-related issues.

\section{References}

1. Yu Dezhi. Perfecting the medical security system is an important way to solve the problem of the high cost of seeing a doctor. Chinese Journal of Hospital Management, 2006, 22 (2): 73-76.

2. Yuan Yingchun. The discourse of "difficult and expensive to see a doctor" changed: 1978-2012. Take the People's Daily as an example. Journal of Anhui Normal University (Humanities and Social Sciences Edition), 2017, 045 (002): 236-244.

3. Xia Tingsong, Lu Zuxuan \& Zhao Zhiguang. Interview results and analysis of the medical personnel group on the issue of "difficult and expensive to see a doctor". China Hospital Management, 2008, 028 (010): 50-53.

4. Chen Yafen. Analysis of the causes of "difficult and expensive to see a doctor". Jiangsu Health Management, 2005, 016 (006): 83-84.

5. Zhou Junxia, Zhou Caixia \& Li Yanxia. Revisiting “Difficult and expensive to see a doctor". World Digest of The Latest Medical Information, 2016, 76 (v.16): 215-219.

\section{Declarations}

\section{Ethics approval and consent to participate}

Written informed consent was obtained from all the participants in the study. And the study was approved by the Ethics Committee of Social Science Foundation Project of Hebei Province and all methods were performed in accordance with the relevant guidelines and regulations.

\section{Consent for publication}

Not applicable 


\section{Availability of data and materials}

Data is available on request via the corresponding author

\section{Competing interests}

The authors declare no conflict of interest.

\section{Funding}

This research was funded by Social Science Foundation Project of Hebei Province "Study on the Status Quo of Catastrophic Medical Expenditure of Rural Residents in Hebei Province and the Construction of Medical Insurance Assistance System", grant number: HB17SH032.

\section{Authors' contributions}

Conceptualization, Ying Pan and Biao Xi; methodology, Lina Yan.; software, Lina Yan; formal analysis, Sihua Chen; investigation, Ying Pan and Sihua Chen; resources, Kejiang Pi; data curation, Lina Yan; writing - original draft preparation, Ying Pan and Shaowen Li; writing - review and editing, Ying Pan, Shaowen Li and Biao Xi; project administration, Biao Xi and Kejiang Pi. All authors have read and agreed to the published version of the manuscript.

\section{Acknowledgements}

We sincerely thank all the participants for their patience in the survey. 